\title{
A Study on the Influential Factors of Work Type and Job Satisfaction of Physically Challenged Laborers on Life Satisfaction
}

\author{
Jae-Chen $\mathrm{KIM}^{*}$, Jong-Jin $\mathrm{KIM}^{* *}$ \\ Received: September 11, 2019. Revised: September 09, 2019. Accepted: October 05, 2019.
}

\begin{abstract}
Purpose - This study is intended to explore influential factors on the life satisfaction of physically challenged laborers preparing for support plans for their future. This is to enjoy a better life and have social opportunities and to review institutional support or plans for implementation to be applied for physically challenged people.

Research design, data, and methodology - 4,161 disabled people participated in the Panel Survey of Employment of the Disabled. Among 2,124 physically challenged people, 957 wage workers (45\%) were primarily extracted in this study, and a total of $581(27 \%)$ with sufficient responses on the questionnaires were finally selected.

Results - First, physical preparation for later life had a positive influence on retired life satisfaction among retirement satisfaction. People showed higher retired life satisfaction. Secondly, physical preparation for later life had a positive influence on satisfaction over relationship after retirement among retirement satisfaction.

Conclusions - In this study, , it was found that job satisfaction was the variable with the highest influential power on life satisfaction. Therefore, it seems to be necessary to proceed a research as to which factors influence life satisfaction in the medium of job satisfaction and also about plans to improve job satisfaction on experts or the disabled.
\end{abstract}

Keywords: Job Satisfaction, Life Satisfaction, Work Type, Physically Challenged Laborers.

JEL Classifications: J14, J28, J81.

\section{Introduction}

For humans, work is to achieve a certain goal unlike instinct-oriented behaviors of animals leading the lives. In order for humans to survive, least conditions are required. It includes to what is naturally acquired, but most of them require physical or mental efforts of humans. This is how humans survive in their lives.

Life satisfaction of the disabled turns out to be different depending on circumstances or characteristics of individuals, and one of the important factors is whether they have job.

* First Author, Ph.D. researcher, Department of Social Welfare, Hansei University, Korea.

Tel: +82-31-559-9114. Email: kjc2364@naver.com

** Corresponding Author, Visiting Professor, Department of Social Welfare, Jungwon University, Korea.

Tel: +82-43-830-8422. Email: 2001j2k@hanmail.net

(c) Copyright: Korean Distribution Science Association (KODISA)

This is an Open Access article distributed under the terms of the Creative Commons Attribution Non-Commercial License (https://creativecommons.org/licenses/by-nc/4.0/) which permits unrestricted non-commercial use, distribution, and reproduction in any medium, provided the original work is properly cited.
Having a job not only means to participate in social activities and product outcomes but also to ultimately improve the life quality and proceed self-realization. Especially, what job means to the disabled is to guarantee human rights and actively make social integration possible. In other words, job is beyond a means of living but serves a role of important means in improving life quality but to participate in society as well as confirm their existence.

Since the last half of the 2000s, institutional support for the employment and welfare of the disabled have been expanded including the Disability Discrimination Act (2008) or Disability Employment Obligation Reinforcement (2009). Therefore, there has been an increasing trend of employing the disabled compared to the past. However, the ratio of part time of disabled laborers is still high compared to the full-timers. In addition, they turned out to suffer from low wage, poor working environment, insufficient convenient facilities, and dysfunctional interpersonal relationship making their life qualities degraded due to unstableness of employment and high unemployment rate. In addition, researches revealing how maintenance of job was a main 
cause of the improvement of life quality indicated how it was important for the disabled to have a job and maintain economically stable life in terms of the life quality of the disabled. Furthermore, working environment, experience of discrimination, work level, or satisfaction on their job was a very important factor to maintain their job(Jeong \& Park, 2012).

According to variables influencing on the life satisfaction of the disabled, many of the factors including demographic factors, work-related factors, and socio-environmental factors turned out to influence on life quality. Demographic factors include gender, age, marital status, academic background, and disability type and severity. Work-related factors include employment type or environment (whether to have help or experience of discrimination), work type, wage, or maintenance of job that turned out to influence on the life satisfaction. In addition, many of the researches have reported how social integration influenced on the lives of the disabled as social factors, and, especially, movement, accessibility, and social support were related to the life satisfaction as physical environment. Other than them, various factors including acceptance of disability or self-esteem were covered in the research as subjective indices. Furthermore, as job-related factors related to working environment suggested beforehand turned out to influence on the satisfaction of the job, their importance has been emphasized as it could be led to the life satisfaction and also how job satisfaction of laborers could change the life quality of them(Templer, 2012).

Hereupon, this study is intended to explore influential factors on the life satisfaction of physically challenged laborers preparing for support plans for them to enjoy a better life and providing them social opportunity and to review institutional support or plans for implementation to be applied to physically challenged people.

\section{Theoretical Backgrounds}

\subsection{Necessity of maintaining the work of physically challenged people}

Compared to how most of the researches dealt with the common definition of work maintenance, the period of work maintenance has been differently defined by each researcher. According to statistical research related to employment in Korea, those hired in a period for more than a month are classified to regular employees. Korea Employment Promotion Agency for the Disabled regards the successful employment period of the disabled as 6 months. The disabled job rehabilitation program in America indicates how job rehabilitation procedure is required to successfully maintain stable job status, and rehabilitation procedure might take several months or even years depending on the request of the subjects for rehabilitation. However, at least 60 days shall pass for job maintenance period when the disabled is employed after completing job rehabilitation service to be defined as successful job rehabilitation (Templer, 2012).

\subsection{Relationship between Employment of Physically Challenged People, Job Satisfaction, and Life Satisfaction}

Enriched life of human is to exert their ability from the work and maintain stable life with economic activities. Importance of career of the disabled is reflected in the increasing trend of population that becomes the disabled at some point in their lives due to industrial disaster or traffic accident along with an increasing request of the disabled in work(Kim, Kang, Ko, \& Kim, 2015).

To the disabled, job makes it feasible to make changes in the motivation, self-confirmation, or relation. Above all, it is an important condition to contribute to social integration. However, the disabled still loses their life functions due to the disability in our society making it difficult for them to maintain an independent life with work. Therefore, they become naturally poor(Krause \& Anson, 1996).

According to the statistics from Ministry of Health and Welfare in 2004, the number of registered disabled people turned out to be $1,967,326$ in an increasing trend every year due to the expansion of scope of disability. Among them, the number of physically challenged people took the biggest portion as 1,049,396. The trend of employment of the physically challenged people in the fourth quarter of 2008 indicated how $25 \%$ of employed disabled people suffering from many types of disabilities were physically challenged people. In addition, they were employed in various types of occupation including the service or technical post compared to job seekers with other types of disabilities. However, simple labor work constituted the highest portion as $27.8 \%$ among types of career where most of the disabled people were employed. At the same time, the average monthly wage of them turned out to be KRW 1.574 million that was significantly lower than the average wage of regular laborers as KRW 2.328 million(Labor Department statistical investigation in April, Ministry of Labor, 2008).

This indicates how it is difficult for the physically challenged jog seekers to be compensated with appropriate wage in the dissatisfying work environment even if they are employed. In fact, it turned out that $30.6 \%$ of them suffered from lack of appropriate career, and $23.6 \%$ of them suffered fro negative attitude of the company towards the disabled even when seeking for the job (Investigation of current status of disabled laborers, 2005). As long as they are not satisfied in the job activities that constitute more than half of their entire lives, it is difficult for them to be satisfied with life. Therefore, seeing as how work plays an important role 
to determine the life quality, job takes an important role for the disabled(Benz \& Frey, 2008).

\subsection{Employment Type of the Physically Challenged People}

Among the economically active population of the disabled, about $67 \%$ turned out to be physically challenged people. Therefore, it shows how the proportion of the physically challenged people is high among the disabled in job market. In addition, among the physically challenged people, about $48.0 \%$ of them turned out to participate in economic activities. Therefore, it was significantly higher than the one of people with disabilities other than physical hardship $(11.9 \%)$ or average economic activity participating rate (38.5\%)(Lee, 2008).

Physically challenged people were employed in various fields of career including service or technical post compared to other job seekers with different types of disability (Lee, 2008), and the proportion of simple manual work was the highest as $29 \%$. The average monthly wage was KRW 1.214 million that was significantly lower than the one of regular workers as KRW 2.719 million. According to the results of investigating the top rated issue in the work on physically challenged people in the [Report of the Actual Conditions of the Disabled in 2008], low wage was the highest as $47.2 \%$. This shows how it is difficult for the employed physically challenged people to receive appropriate wage in dissatisfying work environment. In addition, according to the results of investigation for why unemployed people or economically inactive people did not work, most of the physically challenged people answered how they were old, there was no appropriate career to pursue, or it was to be difficult to work due to their severe disabilities. This indicates how age, work type, and a degree of disability might influence on whether to be employed or not(Connolly \& Viswesvaran, 2000).

\section{Research and Analysis}

\subsection{Research Subjects}

This study has used raw data of the Panel Survey of Employment for the Disabled in order to explore factors influencing on the life satisfaction of the physically challenged people. Panel Survey of Employment of the Disabled is a longitudinal survey conducted to establish and evaluate the employment policies of the disabled providing fundamental data about the disabled since 2008. 4,161 disabled people participated in the Panel Survey of Employment of the Disabled. Among 2,124 physically challenged people, 957 wage workers $(45 \%)$ were primarily extracted in this study, and total 581 (27\%) with sufficient responses on the questionnaires were finally selected.

\subsection{Research Investigation}

Investigation data of this study have been utilized with raw data in the third investigation from the 2nd wave as the panel survey in 2018 conducted by Korea Employment Agency for the Disabled (2018b). Establishing multiple panels near the labor market, the number of samples was maximized making it feasible to clearly identify the causes and results related to employment as an advantage. There were 4,577 members in the panel participating in the 2nd Wave Investigation in 2018, and investigation data from total 2,568 people including 2,250 physically challenged people (49.2\%) and 318 brain disabled people $(6.9 \%)$ (total 2,568) people were used.

\subsection{Measuring Tools}

\subsubsection{Dependent Variables}

Daily life satisfaction used for measuring life satisfaction as an independent variable was comprised of nine questions of family relation, relationship with friends, residential area, health status, monthly income, leisure, job, marital life, and overall satisfaction. Each of the questions in this satisfaction was to be checked according to 5-score Likert criteria from 'very dissatisfied (score 1)' to 'very satisfied (score 5) on daily life satisfaction of physically challenged workers. Therefore, a range of score for satisfaction was fro 9 to 45 , and the higher the score was, the higher the satisfaction level was. Cronbach's $\alpha$ coefficient in this study was .86 as a confidence level to be available with statistical analysis needed for the purpose of research(Lim, Kim, \& Shin, 2013).

\subsubsection{Independent Variables}

Independent variables of this study were set to be the demographic characteristics, disability-related characteristics, and job-related characteristics. Demographic characteristics included gender, age, marital status, and the highest level of education. Disability-related characteristics included a degree of disability, current disability status, duplicated disability, and whether to have chronic disability. In addition, job-related characteristics included employment type, work environment, whether to be helped, opinion on the current work, and experience of discrimination( $\mathrm{Na} \&$ Ryu, 2002).

Among job-related characteristics, 'whether to consider or help with work environment' indicates the experience of consideration for work adjustment, work hours adjustment, and related experience, support for the commute, official work supplement (prepare for the documents or phone work), work support (delivery or assembly of objects, etc.), communication support (sign language communication, reading by proxy, or writing by proxy, etc.), movement 
support (movement in the company or business trip), daily lives support in work (eating or restroom aid). Opinion on the current job was comprised of questions asking the usefulness if employed for jog with same knowledge or function learned in the current work. In addition, 'experience of discrimination.' is comprised of 4 points Likert on the experience of discrimination in daily lives, job seeking activities, preparing for employment, and experience of discrimination in the work. Responding from 'none' (score 1) to 'very much' (score 4), the higher the score is, the more experience subjects have in discrimination. Cronbach' $\alpha$ in this study was .85 as an appropriate confidence level(Park, Kim \& Kang, 2010).

On the other hand, 'satisfaction on work' is comprised of total 12 items including wage, stability, work contents, work environment, interpersonal relationship, and welfare and comprised of 5 points Likert. Responding from 'very dissatisfied' (score 1) to 'very satisfied (score), the higher the score is, the higher the level of satisfaction is. Cronbach $\alpha$ in this study was .91 that was high confidence level(Roh, 2012).

\subsection{Data Analysis}

This study has analyzed the extracted data as follows in the use of SPSS 21.0 to identify influential factors on the life satisfaction of the physically challenged people.

First of all, frequently analysis and descriptive statistics were conducted to identify the general characteristics of physically challenged laborers (demographic characteristics, disability related characteristics, and job related characteristics).

Secondly, hierarchical multiple regression analysis was conducted to analyze the influential factors on the life satisfaction.

\section{Analysis Results}

\subsection{Characteristics of job satisfaction}

According to the results of job related characteristics, as for employment type, there were 371 part timers (63.9\%) that were higher than the number of full timers as 210 (36.1\%). As for consideration and help in the work environment, there were $511(88.0 \%)$ and 522 (89.8) disabled people who responded how consideration on the adjustment of work and work hours was not needed, respectively. Hereupon, there were 23 of them (4.0\%) who responded to have received assistance or consideration from others. Most of them (558 people, 96.0\%) have responded not to have received help or that assistance was not necessary.

In addition, according to the results from 368 disabled subjects except for the insufficient responses for the experience of discrimination (1.35 \pm .57 ), 69.0\% (401 people) responded that they have no experience in discrimination at all. $28.1 \%$ (163) responded 'much,' followed by $0.9 \%$ (5) with 'very much.' Therefore, $31.1 \%$ of them turned out to be discriminated. As for discrimination when seeking for jobs or

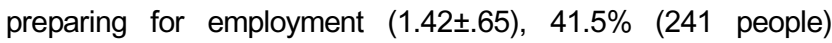
responded not to have any experience followed by $18.1 \%$ (105 people) with 'little,' 2.9\% (17 people) with 'much,' and $0.9 \%$ (5 people) with 'very much.' Therefore, $21.9 \%$ of subjects turned out to be discriminated. In addition, as for discrimination at work (1.22 \pm .47$), \quad 80.2 \%$ (466 people) responded not to have any experience. Therefore, they turned out to be less discriminated compared to daily lives or when seeking for jobs or preparing for employment.

Furthermore, according to the results of opinion on job, $57.8 \%$ (336 people) of subjects responded 'normal' on whether they believed how their current job level was lower then their academic background followed by $26.5 \%$ (154 people) for 'no' and 1.7\% (10 people) for 'very negative.' Therefore, $86.0 \%$ of the entire subjects turned out to regard their current work level to be higher than average compared to their academic background. In addition, as for whether their current work level was lower than technical skills of them, $56.3 \%$ (327 subjects) turned out to respond 'normal' followed by $29.1 \%$ (169 people) with 'no' and $1.9 \%$ (11 people) with 'very negative.' Therefore, the number of subjects $(87.3 \%)$ who believed that their current work level was higher than average compared to their technical skills was higher than the one (12.8\%) who did not believe so. Lastly, on the question as to whether their work knowledge and function were useful to other jobs in the same career type, 53.9\% (313 subjects) have responded 'normal' followed by $28.2 \%$ (164 people) with 'a bit positive' and $1.4 \%$ ( 8 people) with 'very positive.' Therefore, the number of subjects $(83.5 \%)$ who believed their current work knowledge and function to be useful turned out to be higher than the one $(16.6 \%)$ who did not believe so.

\subsection{Influential Factors of Physically Challenged Laborers on Life Satisfaction}

Results of regression analysis conducted in order to analyze influential factors of the physically challenged laborers on their life satisfaction are shown in the <Table 1>. Model 1 was applied with demographic characteristics, and model 2 was applied with job related characteristics on the regression formula identifying how they influenced on the life satisfaction. Model 3 was applied with job satisfaction identifying the increase in significant explanatory variable. On the other hand, according to the results of reviewing multicollinearity, VIF (variance inflation factor) turned out to be closer to $1(1.02 \sim 1.99)$ in all three models. Therefore, it was shown that there was no issue with multicollinearity.

According to the results of entering demographic characteristics; gender, age, marital status, and the highest 
level of education on model 1, regression formula turned out to be significant $(\mathrm{F}=35.411, \mathrm{p}<.001)$, and marital status $(t=10.806, \quad p<.001)$ and the highest level of education $(t=5.043, p<.001)$ turned out to be variables significantly influencing on the life satisfaction. In other words, the more likely it was for them not to have spouse and to have higher level of education, the more they satisfied with their lives. Entered independent variables turned out to have explanatory power of $19.7 \%$.

According to the results of entering job-related characteristics such as employment type, work environment, consideration or whether to receive assistance, experience of discrimination, and opinion on their current work in mode 2, regression formula turned out to be significant $(F=8.406$, $\mathrm{p}<.001)$, and marital status $(\mathrm{t}=8.837, \mathrm{p}<.001)$, the highest level of education ( $t=4.003, p<.001)$, work type $(t=3.808$, $\mathrm{p}<.001)$, experience of discrimination at work $(\mathrm{t}=2.676$, $\mathrm{p}<.01$ ), and usability of knowledge or skill learned from the current work $(t=2.771, p<.01$ turned out to be variables influencing on life quality. This shows that the less likely it is for them to have experience of discrimination at work, and the higher the level of usability of knowledge or function related to work, the higher their life satisfaction turns out to be. Explanatory power of variables entered in the model 3 on life satisfaction was $30.2 \%$.

According to the result of entering the entire job satisfaction of wage, stability, work contents, working environment, and time in the model 3 , regression formula turned out to be significant $(F=25.881, p<.001)$. Marital status $(t=11.808, p<.001$, the highest level of education $(t=2.977, p<.01)$, work type $(t=3.507, p<.01)$, experience of discrimination at work $(\mathrm{t}=-2.300, \mathrm{p}<.05)$, and job satisfaction (t-15.420, $\mathrm{p}<.001$ ) turned out to influence on life quality. Among them, job satisfaction turned out to be a variable with higher influential power $(\beta=.595)$ compared to other independent variables. Explanatory power of this model was high as $58.6 \%$. Therefore, it was known that the higher the job satisfaction of physically challenged laborers was, the higher their life satisfaction turned out to be. This material is organized as shown in <Table 1> below.

Table 1: Influential Factors of Physically Challenged Laborers on Life Satisfaction

\begin{tabular}{|c|c|c|c|c|c|c|c|}
\hline & \multirow[t]{2}{*}{ Variable } & \begin{tabular}{|c|} 
nonstandardization \\
factor
\end{tabular} & $\begin{array}{c}\text { Standardization } \\
\text { factor }\end{array}$ & \multirow[t]{2}{*}{$t$} & \multirow[t]{2}{*}{ VIF } & \multirow[t]{2}{*}{$\mathbf{R}^{2}$} & \multirow[t]{2}{*}{$\mathbf{F}$} \\
\hline & & B & Beta & & & & \\
\hline \multirow{5}{*}{ Model1 } & (Constant) & 3.135 & .000 & $26.747^{\star \star \star}$ & & \multirow{5}{*}{.197} & \multirow{5}{*}{$35.411^{* * *}$} \\
\hline & Gende & .010 & .009 & .227 & 1.076 & & \\
\hline & Age & .003 & .006 & .147 & 1.147 & & \\
\hline & Marital status & .448 & .417 & $10.806^{* * *}$ & 1.162 & & \\
\hline & Academic background & .206 & .209 & $5.043^{\star * \star}$ & 1.106 & & \\
\hline \multirow{9}{*}{ Model2 } & (Constant) & 3.254 & .000 & $9.919^{\star \star \star}$ & & \multirow{9}{*}{.302} & \multirow{9}{*}{$20.356^{\star \star * *}$} \\
\hline & Gende & -.036 & -.031 & -.648 & 1.077 & & \\
\hline & Age & .030 & .056 & 1.037 & 1.147 & & \\
\hline & Marital status & .457 &. .424 & $8.837^{\star \star \star}$ & 1.162 & & \\
\hline & Academic background & .204 & .204 & $4.003^{\star \star \star}$ & 1.103 & & \\
\hline & Employment type & .251 & .188 & $3.808^{* * *}$ & 1.106 & & \\
\hline & $\begin{array}{l}\text { Whether to have consideration or assistance } \\
\text { in the work environment }\end{array}$ & .098 & .094 & 1.889 & 1.900 & & \\
\hline & Experience of discrimination & -.185 & -.177 & $-2.676^{\star \star}$ & 1.977 & & \\
\hline & Work utilization for duties & .082 & .129 & $2.771^{\star \star}$ & 1.977 & & \\
\hline \multirow{10}{*}{ Model3 } & (Constant) & 1.652 & .000 & $6.037^{\star \star \star}$ & & \multirow{10}{*}{.586} & \multirow{10}{*}{$25.881^{* * *}$} \\
\hline & Gende & .040 & .035 & .940 & 1.081 & & \\
\hline & Age & .022 & .040 & .964 & 1.147 & & \\
\hline & Marital status & .472 & .438 & $11.808^{* * *}$ & 1.117 & & \\
\hline & Academic background & .118 & .118 & $2.977^{\star \star}$ & 1.988 & & \\
\hline & Employment type & .179 & .134 & $3.507^{\star *}$ & 1.985 & & \\
\hline & $\begin{array}{l}\text { Whether to have consideration or assistance } \\
\text { in the work environment }\end{array}$ & .053 & .052 & 1.045 & 1.902 & & \\
\hline & Experience of discrimination & -.123 & -.117 & $-2.300^{*}$ & 1.955 & & \\
\hline & Work utilization for duties & .002 & .003 & .068 & 1.018 & & \\
\hline & Life satisfaction & .564 & .595 & $15.420^{\star * *}$ & 1.008 & & \\
\hline
\end{tabular}

${ }^{*} p<.05,{ }^{* *} p<.01,{ }^{* * *} p<.001$

a: Dependent Variables: Satisfaction in Life 


\section{Conclusion}

\subsection{Conclusion Summary}

The purpose of this study is to explore how demographic characteristics, disability characteristics, job-related characteristics, and job satisfaction influence on the life satisfaction of physically challenged laborers by using the data from Panel Survey of Employment for the Disabled in the 2nd Wave in 2018 conducted in the employment development associate in Korean Employment Agency for the Disabled. Hereupon, this study is intended to identify characteristics of physically challenged workers based on the research results discussing about social support and implementation plans for improving the life satisfaction.

First of all, according to the results of identifying demographic characteristics of physically challenged workers, there were more men than women, and most of them were 45 years or older. A majority of them were married and high school graduates. This reflects the report from research for how men were in advantageous position than women for employment of the physically challenged people. In fact, the employment rate of physically challenged male applicants $(61.0 \%)$ is three times higher than the one for women (22.0\%). Especially, among the entire population in Korea, it shows the difference that is two times $(39.5 \% \mathrm{p})$ higher than the one of employment rate $(21.6 \%)$ of men $(71.8 \%)$ and women (50.2\%) (Korean Employment Agency for the Disabled, 2014). Therefore, there is a need to come up with program for employment support for physically challenged female applicants and a plan for reducing unemployment rate of female workers. In addition, it seems to be necessary to proceed more multi-faceted review and investigation on actual conditions on demographic characteristics influencing on the employment based on previous studies for how married, old, and highly educated people tend to be more likely unemployed.

According to jog-related characteristics, most of the subjects responded how there was no need to adjust the duties or work hours and also the assistance. In addition, there was many subjects who felt less discrimination at work than when seeking for job or preparing for employment, and also that current work level was higher than their academic background, and knowledge and function of work were highly useful.

Such results seem to be derived as there were many subjects with low level of consideration or assistance, experience of discrimination, and high level of education that the appropriateness with their education or technical level or usefulness of knowledge and function of work turned out to be high. However, considering how most of them were part-timers, and also how whether to be a full-timer was a core index of employment stability (Choi, 2009), it means how they are not able to maintain stable life with part time work, and also to secure life quality. This implies how unequal employment opportunity on the disabled is of a fundamental issue requiring national attention and improvement. At the same time, it is required to find solution for employment issue of the disabled in terms of employment environment.

On the other hand, overall job satisfaction of physically challenged workers turned out to be higher than the average. Communication, interpersonal relationship, work contents, and work hours indicated high level of satisfaction, while low level of satisfaction was shown on education and training opportunity, potential for individual development, wage or income, and welfare. This is the result that the better the interpersonal relationship is, the higher the level of job satisfaction is, and the longer the work maintenance period turns out to be. At the same time, this is similar with the study suggesting the importance of employment type or income beyond whether to be employed for the disabled.

\subsection{Conclusion Proposal}

According to the results of life satisfaction of the physically challenged workers, they showed the level of satisfaction in about average. They had high level of satisfaction on family relationship, marriage life, relationship with friends, and residential areas, but low level of satisfaction on leisure activities. This was consistent with the result made by Jae-guk Park (2015) or how the level of satisfaction within individuals was lower than the level of satisfaction between individuals, and regarded how satisfaction on family relationship could improve the life quality with the social support of family. Life satisfaction is influenced by economic ability. As income level turned out to be an important aspect of life satisfaction, it has been mentioned how it was required to guarantee economic support or a certain amount of income for the pleasant lives of the disabled(Chung \& Noh, 2007).

With this study, it was found that job satisfaction was the variable with the highest influential power on life satisfaction. Therefore, it seems to be necessary to proceed a research as to which factors influence on life satisfaction in the medium of job satisfaction and als about plans to improve job satisfaction on experts or the disabled.

\section{References}

Benz, M., \& Frey, B. S. (2008). Being Independent is a Great Thing: Subjective Evaluations of Self-Employment and Hierarchy. Economica, 75(298), 362-383.

Bouma, G., Haidar, A., Nyland, C., \& Smith, W. (2003). Work, religious diversity and Islam. Asia Pacific Journal of Human Resources, 41(1), 51-61.

Cho, S. W., \& Nam, J. H. (2013). The study of job satisfaction factors of women with disabilities. Journal of Special Education \& Rehabilitation Science, 52(4), 
225-241.

Choi, U. J., Park, K. S., \& Lee, S. H. (2014). A study on the determinant factors affecting the employment status of the middle and old aged disabled women. Disability \& Employment, 24(3), 3-26.

Chung, M. S., \& Noh, S. H. (2007). A study on factors influencing the community integration of the middle aged and elders with physical disabilities. Journal of Community Welfare, 21, 21-50.

Connolly, J. J., \& Viswesvaran, C. (2000). The role of affectivity in job satisfaction: A meta-analysis. Personality and Individual Differences, 29(2), 265-281.

Eisenberger, R., Armeli, S., Rexwinkel, B., Lynch, P. D., \& Rhoades, L. (2001). Reciprocation of perceived organizational support. Journal of Applied Psychology, 86(1), 42-51.

Furnham, A., Chamorro-Premuzic, T., \& McDougall, F. (2002). Personality, cognitive ability, and beliefs about intelligence as predictors of academic performance. Learning and Individual Differences, 14(1), 47-64.

Hiraishi, K., Yamagata, S., Shikishima, C., \& Ando, J. (2008). Maintenance of genetic variation in personality through control of mental mechanisms: A test of trust, extraversion, and agreeableness. Evolution and Human Behavior, 29(2),

Hoffman, B. J., Blair, C. A., Meriac, J. P., \& Woehr, D. J. (2007). Expanding the criterion domain? A quantitative review of the OCB literature. Journal of Applied Psychology, 92(2), 555-566.

Hwang, J. E., \& Jung, M. S. (2011). A study on the factors influencing to job satisfaction for disabled workers in social enterprise. Disability \& Employment, 21(2), 247-271.

Im, J. H., \& Whang, Y. W. (2012). A study on the affecting factors of the employment of the persons with visual impairments. The Korean Journal of Visual Impairment, 28(3), 47-67.

Jeong, W. C., \& Park, Y. J. (2012). A study on the predictor variables of employment in the persons with psychiatric disabilities. Disability \& Employment, 22(4), 187-210.

Kim, D. J., \& Ko, M. S. (2012). The study of economic activity of intellectual disables related to variables. Journal of Intellectual Disabilities, 14(1), 241-261.

Kim, J. A., Na, W. H., \& Kim, J. M. (2013). A study on factors affecting employment and duration of job maintenance of women with disabilities. Journal of Special Education \& Rehabilitation Science, 52(4), 321-338.

Kim, J. J., Park, J. K., \& Kim, I. S. (2014). Analysis on the influence factors on job maintenance and satisfaction of individuals with physical disabilities. The Journal of Special Education: Theory and Practice, 1544), 559-585.

Kim, S. W., Kang, D. U., Ko, A. R., \& Kim, J. H. (2015). Study of determinant factors for women with severe and minor disabilities in part-time jobs. Disability \& Employment, 25(1), 104-134.
Krause, J., \& Anson, C. (1996). Employment after spinal cord injury: Relation to selected participant characteristics. Archives of Physical Medicine \& Rehabilitation, 77, 737-743.

Kim, T.-Y., \& Leung, K. (2007). Forming and reacting to overall fairness: A cross-cultural comparison. Organizational Behavior and Human Decision Processes, 104(1), 83-95.

Lee, C. S., \& Kim, M. S. (2015). The study on psycho-social attributes and longitudinal change influencing employment determining of persons with acquired abilities. Disability \& Employment, 25(2), 5-27.

Lee, H. Y. (2008). A study about the influence on the job maintenance period of individual characteristic, job training, job satisfaction by disability type employment workers. Social Welfare Policy, 32(3), 109-134.

Lee, J. S. (2008). A study about decisive factors on employment of a person with physical disability and/or Cerebral palsy. Disability \& Employment, 18(2), 57-82.

Lee, J. S., \& Baek, E. R. (2008). A study on the current situation and the factors affecting wages of the women workers with disabilities in Korea. Disability \& Employment, 18(1), 93-109.

Lidal, I. B. Huynh, T. K., \& Biering S. F. (2007). Return to work following spinal cord injury: a review. Disability rehabilitation, 291), 1341-1375.

Lim, E. J., Kim, S. J., \& Shin, H. U. (2013). A study on the analysis of employment decision factor of the visually impaired using data mining technique. Disability \& Employment, 23(1), 273-302.

Mank, D., O'Neil, C., \& Jensen, R. (1998). Quality in supported employment: a new demonstration of the capabilities of persons with severe disabilities. Journal of Vocational Rehabilitation, 11(1), 83-95.

$\mathrm{Na}$, W. H., \& Ryu, J. J. (2002). A study on the Labor-productivity of the persons with disability who work at the manufacturing factories. Journal of Rehabilitation Research, 6(2), 1-23.

Oh, S. R. (2008). A study about the predictor variables of employment of persons with disabilities. Social Welfare Policy, 34, 255-275.

Ok, J. D. (2007). A study on job satisfaction of factory workers with a hearing disorder. The Journal of Special Education, 8(3), 367-382.

Park, J. K., Kim, J. J., \& Kang, Y. J. (2010). Jog satisfaction of workers with disabilities. Disability \& Employment, 20(1), 5-32.

Roh, S. H. (2012). The Longitudinal study on the factors of the employment and employment types among disabled elderly. Disability \& Employment, 22(3), 51-82.

Templer, K. J. (2012). Five-Factor Model of Personality and Job Satisfaction: The Importance of Agreeableness in a Tight and Collectivistic Asian Society. Applied Psychology, 61(1), 114-129. 